\title{
Saponin 6 derived from Anemone taipaiensis induces U87 human malignant glioblastoma cell apoptosis via regulation of Fas and Bcl-2 family proteins
}

\author{
CHEN-CHEN JI $^{1 *}$, HAI-FENG TANG ${ }^{2 *}$, YI-YANG HU ${ }^{3 *}$, YUN ZHANG $^{4}$, MIN-HUA ZHENG $^{3}$, \\ HONG-YAN QIN ${ }^{3}$, SAN-ZHONG LI $^{1}$, XIAO-YANG WANG ${ }^{5}$, ZHOU FEI $^{1}$ and GUANG CHENG ${ }^{1}$
}

\begin{abstract}
${ }^{1}$ Department of Neurosurgery, Xijing Institute of Clinical Neuroscience; ${ }^{2}$ Institute of Materia Medica, School of Pharmacy; ${ }^{3}$ State Key Laboratory of Cancer Biology, Department of Medical Genetics and Developmental Biology; ${ }^{4}$ Department of Immunology, Fourth Military Medical University, Xi'an, Shaanxi 710032; ${ }^{5}$ Department of Pharmacy, The 302nd Hospital of Chinese P.L.A., Beijing 100039, P.R. China
\end{abstract}

Received February 11, 2015; Accepted January 7, 2016

DOI: $10.3892 / \mathrm{mmr} .2016 .5287$

\begin{abstract}
Glioblastoma multiforme (GBM) is the most common and aggressive type of brain tumor, and is associated with a poor prognosis. Saponin 6, derived from Anemone taipaiensis, exerts potent cytotoxic effects against the human hepatocellular carcinoma HepG2 cell line and the human promyelocytic leukemia HL-60 cell line; however, the effects of saponin 6 on glioblastoma remain unknown. The present study aimed to evaluate the effects of saponin 6 on human U87 malignant glioblastoma (U87 MG) cells. The current study revealed that saponin 6 induced U87 MG cell death in a dose- and time-dependent manner, with a half maximal inhibitory concentration $\left(\mathrm{IC}_{50}\right)$ value of $2.83 \mu \mathrm{M}$ after treatment for $48 \mathrm{~h}$. However, saponin 6 was needed to be used at a lesser potency in HT-22 cells, with an $\mathrm{IC}_{50}$ value of $6.24 \mu \mathrm{M}$. Cell apoptosis was assessed by flow cytometry using Annexin V-fluorescein isothiocyanate/propidium iodide double staining. DNA fragmentation and alterations in nuclear morphology were examined by terminal deoxynucleotidyl transferase-mediated dUTP nick end labeling and transmission electron microscopy, respectively. The present study demonstrated that treatment with saponin 6 induced cell apoptosis in U87 MG cells, and resulted in DNA fragmentation and nuclear morphological alterations typical of apoptosis. In addition, flow cytometric analysis revealed that saponin 6 was able to induce
\end{abstract}

Correspondence to: Professor Guang Cheng or Professor Zhou Fei, Department of Neurosurgery, Xijing Institute of Clinical Neuroscience, Fourth Military Medical University, 169 Changle Road, Xi'an, Shaanxi 710032, P.R. China

E-mail: chg16801@163.com

E-mail: feizhou@fmmu.edu.cn

${ }^{*}$ Contributed equally

Key words: saponin 6, glioblastoma, apoptosis, Anemone taipaiensis, Fas, Bcl-2 cell cycle arrest. The present study also demonstrated that saponin 6-induced apoptosis of U87 MG cells was attributed to increases in the protein expression levels of Fas, Fas ligand, and cleaved caspase-3, -8 and -9 , and decreases in the levels of B-cell lymphoma 2. The current study indicated that saponin 6 may exhibit selective cytotoxicity toward U87 MG cells by activating apoptosis via the extrinsic and intrinsic pathways. Therefore, saponin 6 derived from A. taipaiensis may possess therapeutic potential for the treatment of GBM.

\section{Introduction}

Glioblastoma multiforme (GBM) is the most common and aggressive type of primary brain malignancy in adults. The prognosis of GBM is generally poor, with a median survival time of 14.6 months (1). GBM is currently treated with surgical resection, radiotherapy and adjuvant temozolomide (TMZ) chemotherapy. Although these treatment regimens have evolved over the years, the improvements have not translated into marked increases in patient survival. GBM is characterized by chemoresistance, and the clinical success of TMZ treatment is limited (2). Previous studies have demonstrated that $>90 \%$ of recurrent gliomas do not respond to the second cycle of TMZ $(3,4)$. In addition, TMZ may induce $C>T / G>A$ transition mutations when DNA mismatch repair is deficient, which can potentially promote tumor progression $(5,6)$. Therefore, there is an urgent requirement for the development of novel effective agents in the treatment of GBM.

Saponins, which are glycosides present in numerous plants, have been reported to exhibit marked cytotoxicity against various types of cancer $(7,8)$. In particular, saponins derived from the rhizomes of Anemone taipaiensis (Ranunculaceae) exhibit potent cytotoxicity toward the human hepatocellular carcinoma cell line HepG2 and the human promyelocytic leukemia cell line HL-60 (9). Furthermore, our previous studies demonstrated that saponin 1 and saponin B, derived from A.taipaiensis, effectively inhibited brain tumor progression $(10,11)$. Following these results, the present study aimed to determine the potential antiglioma activities of other saponins derived from A.taipaiensis. 
In the present study, the effects of A.taipaiensis-derived saponin $6(3 \beta-\mathrm{O}-\{\alpha-\mathrm{L}-$ rhamnopyranosyl- $(1 \rightarrow 2)-[\beta-\mathrm{D}$-gluco pyranosyl-( $1 \rightarrow 4)]-\alpha$-L-arabinopyranosyl $\}$ oleanolic acid) on the viability and apoptosis of human U87 malignant glioblastoma (U87 MG) cells were evaluated. In addition, the molecular mechanisms underlying these effects were explored.

\section{Materials and methods}

Chemical reagents. Saponin 6 (>98\% purity) was provided by Professor Tang (Institute of Materia Medica, School of Pharmacy, Fourth Military Medical University, Xi'an, China). The purity of saponin 6 was determined using a Dionex P680 high pressure liquid chromatography pump (Dionex; Thermo Fisher Scientific, Inc., Waltham, MA, USA) equipped with a UV 70 $\mathrm{UV} / \mathrm{V}$ is detector at $206 \mathrm{~nm}$, and a YMC-Pack R\&D ODS-A column (YMC Co.,Ltd., Kyoto, Japan). Saponin 6 was dissolved in dimethyl sulfoxide (DMSO; Thermo Fisher Scientific, Inc.) and diluted with water to generate the $111.61 \mu \mathrm{M}$ stock solution, containing no more than $0.1 \%$ DMSO. The stock solution was stored in aliquots at $-20^{\circ} \mathrm{C}$. Prior to experimentation, the stock solution was thawed, sterilized by filtration through a $0.22-\mu \mathrm{m}$ sterile filter (EMD Millipore, Billerica, MA, USA), and diluted in Dulbecco's modified Eagle medium (DMEM) supplemented with $10 \%$ fetal bovine serum (Gibco; Thermo Fisher Scientific, Inc.) containing 0.1\% DMSO. DMEM containing 0.1\% DMSO was used as the vehicle control in subsequent experiments.

Cell culture. The human U87 MG cell line and the murine HT-22 hippocampal neuronal cell line were purchased from the American Type Culture Collection (Manassas, VA, USA). The cells were cultured in DMEM supplemented with $10 \%$ fetal bovine serum (Gibco; Thermo Fisher Scientific, Inc.) at $37^{\circ} \mathrm{C}$ in a humidified incubator containing $5 \% \mathrm{CO}_{2}$.

Cell viability. Cell viability was determined using the Cell Counting kit 8 (CCK-8) assay (Dojindo Molecular Technologies, Inc., Kumamoto, Japan) $(12,13)$. Briefly, U87 MG and HT-22 cells were seeded in 96 -well plates $\left(2 \times 10^{4}\right.$ cells/well) and incubated overnight. Subsequently, the cells were treated with saponin 6 at various concentrations (vehicle control, 1.79, $3.57,7.14$ and $14.28 \mu \mathrm{M}$ ) for 24 or $48 \mathrm{~h}$. The optical density was measured at $450 \mathrm{~nm}$ using a Model 680 microplate reader (Bio-Rad Laboratories, Inc., Hercules, CA, USA).

Cell morphology and terminal deoxynucleotidyl transferase-mediated dUTP nick end labeling (TUNEL) assay. DNA fragmentation was assessed using TUNEL staining (Roche Molecular Diagnostics, Pleasanton, CA, USA). Briefly, U87 MG cells were seeded in 24-well plates (1x105 cells/well) and incubated overnight. Subsequently, the cells were treated with 2.83 or $5.66 \mu \mathrm{M}$ saponin 6 for $24 \mathrm{~h}$, washed with phosphate-buffered saline (PBS), and fixed in $4 \%$ paraformaldehyde at $4^{\circ} \mathrm{C}$ for $10 \mathrm{~min}$. Following two PBS washes, the cells were permeabilized by incubating with $0.1 \%$ sodium citrate $/ 0.1 \%$ Triton X-100 for $20 \mathrm{~min}$. The cells were then washed again and incubated with the TUNEL reaction mixture at $37^{\circ} \mathrm{C}$ for 60 min. Cell nuclei were counterstained with Hoechst 33342 (Beyotime Institute of Biotechnology, Haimen, China). Cell morphology was examined under a fluorescence microscope
(FV-1000; Olympus Corporation, Tokyo, Japan). Images of the cells were acquired using a Q-imaging video camera (QImaging, Surrey, BC, Canada).

Quantitation of apoptosis by flow cytometry. Cell apoptosis was determined by flow cytometry using Annexin V-fluorescein isothiocyanate (FITC)/propidium iodide (PI) double staining. Briefly, U87 MG cells were seeded in 24-well plates ( $2 \times 10^{5}$ cells/well) and incubated overnight. Subsequently, the cells were treated with vehicle only, $2.83 \mu \mathrm{M}$ or $5.66 \mu \mathrm{M}$ saponin 6 for $24 \mathrm{~h}$. Following the treatment, the cells were harvested by trypsinization, washed with cold PBS, and double-stained with Annexin V-FITC and PI (Immunotech S.A., Marseilles, France) at room temperature for $15 \mathrm{~min}$. The cells were immediately subjected to flow cytometric analysis using a FACSCalibur ${ }^{\mathrm{TM}}$ system (BD Biosciences, Franklin Lakes, NJ, USA). Data were processed using ModFit software version 3.0 (Verity Software House, Topsham, ME, USA) and presented in a quadrantal diagram.

Ultrastructural studies by transmission electron microscopy (TEM). U87 MG cells were seeded in culture dishes $\left(2 \times 10^{5}\right.$ cells $\left./ \mathrm{ml}\right)$ and incubated overnight. Subsequently, the cells were treated with vehicle only, 2.83 or $5.66 \mu \mathrm{M}$ saponin 6 for $24 \mathrm{~h}$. The cells were harvested by trypsinization and fixed with $2.5 \%$ glutaraldehyde (PBS, pH 7.4) at $4^{\circ} \mathrm{C}$ overnight. The cells were then post-fixed in $1 \%$ buffered osmium tetroxide at room temperature for $2 \mathrm{~h}$, dehydrated through a graded series of ethanol solutions, and embedded in Poly/Bed (Polysciences, Warrington, PA, USA) for $24 \mathrm{~h}$ at $60^{\circ} \mathrm{C}$. Ultrathin sections (70-90 nm) were cut on an ultramicrotome and double-stained with uranyl acetate and lead citrate. The cell TEM micrographs were acquired using a JEM-2000EX electron microscope (JEOL, Ltd., Tokyo, Japan).

Cell cycle analysis. U87 MG cells were seeded in 6-well plates ( $2 \times 10^{5}$ cells $\left./ \mathrm{ml}\right)$ and incubated overnight. Subsequently, the cells were treated with vehicle only, $2.85 \mu \mathrm{M}$ or $5.66 \mu \mathrm{M}$ saponin 6 for $24 \mathrm{~h}$. Following the treatment, the cells were collected by trypsinization, washed in cold PBS, and fixed in $75 \%$ ethanol at $4^{\circ} \mathrm{C}$ overnight. The fixed cells were subsequently washed with cold PBS and incubated with $50 \mu \mathrm{g} / \mathrm{ml}$ PI solution containing $50 \mu \mathrm{g} / \mathrm{ml}$ RNase A (Sigma-Aldrich, St. Louis, MO, USA) at room temperature for $30 \mathrm{~min}$ in the dark. Cell cycle analysis was performed using a flow cytometer (FACSCalibur ${ }^{\mathrm{TM}}$; BD Biosciences) and ModFit software (Verity Software House).

Western blot analysis. U87 MG cells were treated with vehicle only, $2.83 \mu \mathrm{M}$ or $5.66 \mu \mathrm{M}$ saponin 6 for $24 \mathrm{~h}$ as previously described. The cells were then lysed in radioimmunoprecipitation assay buffer $[150 \mathrm{mM} \mathrm{NaCl}, 1 \% \mathrm{NP}-40,0.5 \%$ sodium deoxycholate, $0.1 \%$ sodium dodecyl sulfate (SDS), $50 \mathrm{mM}$ Tris- $\mathrm{HCl}$, $\mathrm{pH}$ 8.0] supplemented with a complete protease inhibitor cocktail (Roche Diagnostics, Basel, Switzerland) at $4^{\circ} \mathrm{C}$ for $30 \mathrm{~min}$. The cell lysates were centrifuged at 15,000 x g for $15 \mathrm{~min}$, and the supernatants were collected. The protein concentrations were determined using a Bicinchoninic Acid Protein Assay kit (Thermo Fisher Scientific, Inc.). Protein samples $(25 \mu \mathrm{g})$ were then separated by $12 \%$ SDS-polyacrylamide gel electrophoresis and transferred to polyvinylidene fluoride membranes 
(EMD Millipore). Subsequent to blocking the membranes in $5 \%$ nonfat dry milk containing $0.1 \%$ Tween-20 (Sigma-Aldrich) for $2 \mathrm{~h}$, the membranes were incubated with polyclonal rabbit anti-Fas (1:500; cat. no. BS1461; Bioworld Technology, Inc., St. Louis Park, MN, USA), polyclonal rabbit anti-Fas ligand (FasL; 1:500; cat. no. BS1122; Bioworld Technology, Inc.), polyclonal rabbit anti-caspase-3 (1:1,000; cat. no. ab90437; Abcam, Cambridge, MA, USA), monoclonal rabbit anti-caspase- 8 (1:800; cat. no. 9496; Cell Signaling Technology, Inc., Danvers, MA, USA), anti-caspase-9 (1:500; cat. no. BS1388; Bioworld Technology, Inc.), polyclonal rabbit anti-B-cell lymphoma 2 (Bcl-2; 1:500; cat. no. BS1511; Bioworld Technology, Inc.), polyclonal rabbit anti-Bcl-2-associated X protein (Bax; 1:500; cat. no. BS2538; Bioworld Technology, Inc.), and mouse monoclonal anti- $\beta$-actin (1:1,000; cat. no. sc-47778; Santa Cruz Biotechnology, Inc., Dallas, TX, USA) antibodies at $4^{\circ} \mathrm{C}$ overnight. The membranes were subsequently washed three times with $0.1 \%$ Tween-20 in PBS (10 min each wash) and incubated with the secondary antibodies bovine anti-mouse IgG-horseradish peroxidase-conjugated (HRP) (cat. no. sc-2371) and bovine anti-rabbit IgG-HRP (cat. no. sc-2370) (both 1:2,000; Santa Cruz Biotechnology, Inc.) for $1 \mathrm{~h}$ at room temperature. Immunoreactive bands were visualized using the enhanced chemiluminescence detection system (GE Healthcare, Uppsala, Sweden). Data were normalized to $\beta$-actin using ImageJ version 1.47 software (imagej.nih.gov/ij/).

Statistical analysis. All data are presented as the mean \pm standard deviation calculated from at least three independent experiments. Data were analyzed using SPSS 20.0 (IBM SPSS, Armonk, NY, USA) or GraphPad Prism 5.01 (GraphPad Software, Inc., La Jolla, CA, USA) software. Differences between groups were analyzed using Student's t-test. $\mathrm{P}<0.05$ was considered to indicate a statistically significant difference.

\section{Results}

Saponin 6 exerts cytotoxic effects against U87 MG cells. The chemical structure and high-performance liquid chromatography (HPLC) chromatographs of saponin 6 are presented in Fig. 1A-C. Saponin 6 was $>98 \%$ pure, as assessed by HPLC. The effects of saponin 6 were initially determined on the cell viability of human U87 MG cells and murine HT-22 hippocampal neuronal cells using the CCK-8 assay. Treatment with saponin 6 significantly decreased U87 MG cell viability in a time- and dose-dependent manner (Fig. 1D). The half maximal inhibitory concentration $\left(\mathrm{IC}_{50}\right)$ of saponin 6 was calculated as $2.83 \mu \mathrm{M}$ following a $48 \mathrm{~h}$ treatment. However, low concentrations of saponin $6(<3.57 \mu \mathrm{M})$ did not significantly affect the viability of HT-22 cells following treatment for $48 \mathrm{~h}$. The $\mathrm{IC}_{50}$ value of saponin 6 against HT-22 cells was $6.24 \mu \mathrm{M}$, which was more than two-fold higher than the value against U87 MG cells (Fig. 1E). These results indicate that saponin 6 may exhibit selective cytotoxicity against glioblastoma cells.

Saponin 6 causes DNA fragmentation, alters nuclear morphology, and induces apoptosis in U87 MG cells. To further investigate saponin 6-induced U87 MG cell death, the present study assessed the effects of saponin 6 on DNA fragmentation, nuclear morphology and cell apoptosis using
TUNEL staining, TEM and flow cytometry, respectively. TUNEL staining detected fragmented DNA, and the TEM micrographs revealed the loss of cellular microvilli and the presence of condensed, fractured and marginalized chromatin following a $24 \mathrm{~h}$ treatment with saponin 6 . In addition, these effects increased with the increasing concentration of saponin 6 (Fig. 2A). Flow cytometric analysis using Annexin V-FITC/PI double staining revealed that saponin 6 significantly increased the number of early and late apoptotic cells in a dose-dependent manner (Fig. 2B and C). In particular, $70 \%$ of cells underwent apoptosis (early or late stage) following a $24 \mathrm{~h}$ treatment with $5.66 \mu \mathrm{M}$ saponin 6 (Fig. 2D). Furthermore, Hoechst 33342 staining revealed the presence of pyknotic nuclei and apoptotic bodies in TUNEL-positive cells (Fig. 2E), further confirming the activation of apoptosis. Although treatment with saponin 6 also increased cell necrosis, this accounted for only a small fraction of cell death induced by saponin 6 (Fig. 2B and C). These results indicate that saponin 6 may induce U87 MG cell death, predominantly via the promotion of cell apoptosis.

Saponin 6 induces $G_{0} / G_{1}$ cell cycle arrest in U87 MG cells. To fully characterize the effects of saponin 6 , cell cycle progression of the U87 MG cells was determined by flow cytometry using PI staining. Treatment with saponin 6 significantly increased the percentage of cells at $\mathrm{G}_{0} / \mathrm{G}_{1}$ phase, and decreased the percentage of cells at $\mathrm{S}$ phase in a concentration-dependent manner (Fig. 3). These results indicate that saponin 6 may induce $\mathrm{G}_{0} / \mathrm{G}_{1}$ arrest in U87 MG cells.

Saponin 6 activates both extrinsic and intrinsic apoptotic pathways in U87 MG cells. To explore the signaling pathways underlying saponin 6-induced cell apoptosis in U87 MG cells, the effects of saponin 6 were determined on the protein expression levels of: The Fas death receptor and its ligand FasL; proteins involved in the extrinsic (death receptor) apoptotic pathway; Bcl-2 family proteins, including Bax (pro-apoptotic) and Bcl-2 (anti-apoptotic); and key regulators of the intrinsic (mitochondrial) apoptotic pathway. Treatment with saponin 6 for $24 \mathrm{~h}$ significantly increased the expression levels of Fas and FasL, and decreased Bcl-2 expression in a dose-dependent manner; however, there were no significant effects on Bax expression (Fig. 4A). These results suggest that saponin 6 may induce U87 MG cell apoptosis via activation of both the extrinsic and intrinsic apoptotic pathways. In addition, the protein expression levels of cleaved caspase-8 (an initiator caspase in the extrinsic pathway), cleaved caspase-9 (an initiator caspase in the intrinsic pathway), and cleaved caspase-3 (an effector caspase in both the extrinsic and intrinsic pathways) were detected. Treatment with saponin 6 significantly increased the expression levels of cleaved caspase- $8,-9$ and -3 in a concentration-dependent manner (Fig. 4B-C). These results are in agreement with the conclusion that saponin 6 may activate both the extrinsic and intrinsic apoptotic pathways in U87 MG cells.

\section{Discussion}

Saponins are natural glycosides that consist of a triterpene or steroid aglycone, with one or more sugar chains. Although these are primarily found in plants, saponins are also produced 

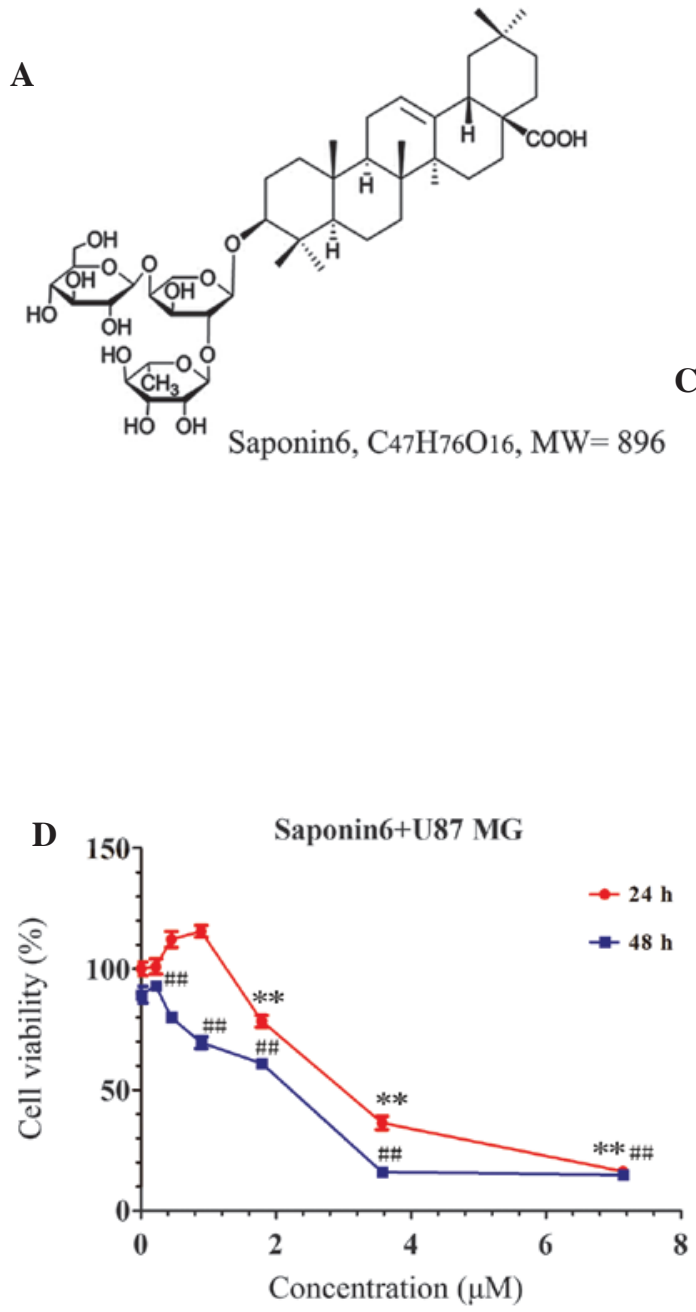

B

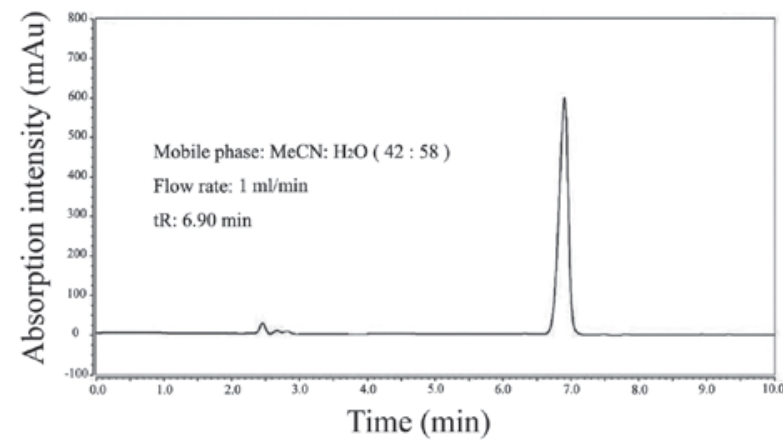

C
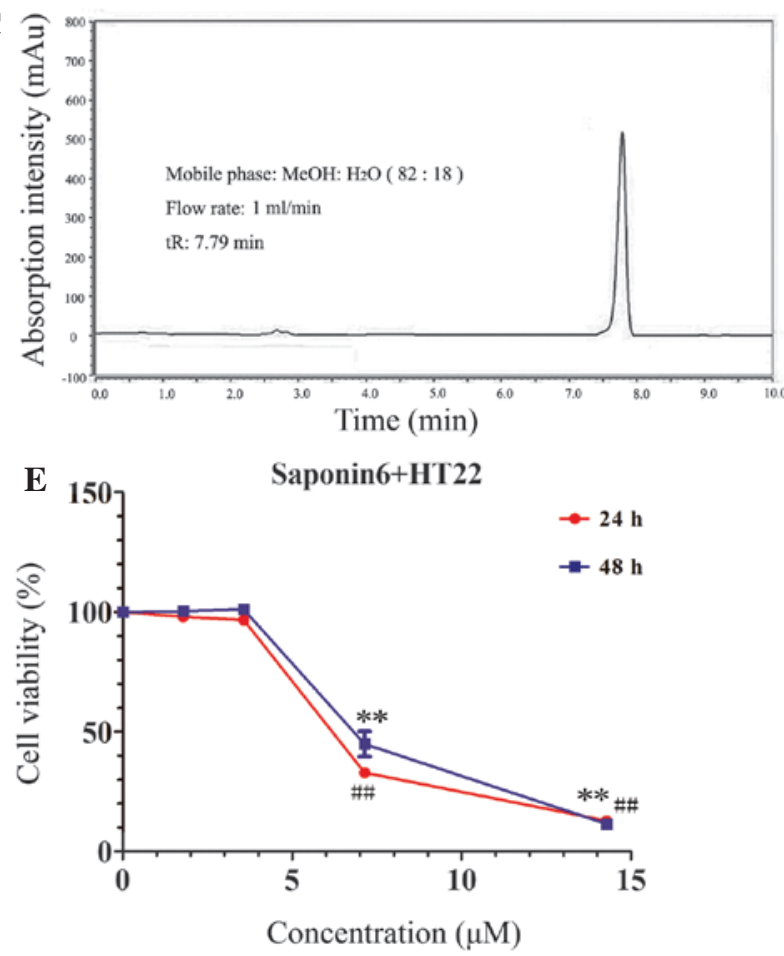

Figure 1. Saponin 6 reduces human U87 MG malignant glioblastoma cell viability. (A) Chemical structure of saponin 6 derived from Anemone taipaiensis. (B and C) Saponin 6 in different mobile phases was separated on a YMC Pack R\&D ODS-A column (4.6x250 mm; YMC Co., Ltd., Japan) using a Dionex P680 liquid chromatography system equipped with a UV170 UV/Vis detector. (D) U87 MG and (E) HT-22 murine hippocampal neuronal cells were treated with saponin 6 at the indicated concentrations for 24 or $48 \mathrm{~h}$. Cell viability was determined using the Cell Counting kit- 8 assay. Data are presented as the mean \pm standard deviation; $n=4 .{ }^{* *} \mathrm{P}<0.01$ vs. the vehicle control group in the 24 -h treatment experiment; ${ }^{\# \#} \mathrm{P}<0.01$ vs. the vehicle control group in the 48 -h treatment experiment. MW, molecular weight.

by certain marine organisms (14). Due to the great variability of their structures, saponins exert diverse biological functions, including anticancer (15), anti-inflammatory (16), antidiabetic (17), and cardioprotective (18) properties. In particular, numerous saponins have recently been reported to inhibit glioma cell proliferation in vitro (19-22) and suppress glioblastoma progression in vivo (21). Our previous studies demonstrated that saponin $\mathrm{B}$ and saponin 1 derived from A. taipaiensis exhibited significant in vitro and in vivo antiglioma activity $(10,11)$. In addition, our previous preliminary structure-activity relationship studies demonstrated that the cytotoxicity of these A.taipaiensis-derived saponins is markedly affected by the length of their oligosaccharide chain at C-3. The greatest potency was observed in compounds with a chain of intermediate length (15). Therefore, the present study hypothesized that saponin 6 derived from A.taipaiensis, which has an oligosaccharide chain of intermediate length, may possess potent antiglioma activity. The results of the present study demonstrated that saponin 6 induced U87 MG cell death in a concentration- and time-dependent manner. Furthermore, saponin $6 \mathrm{had}$ an $\mathrm{IC}_{50}$ value of $2.83 \mu \mathrm{M}$ following a $48 \mathrm{~h}$ treatment. Although saponin 6 also exerted cytotoxic effects against noncancerous HT-22 hippocampal neuronal cells, its potency toward HT-22 cells was much lower than that toward U87 MG cells, thus indicating differential cytotoxicity against cancer cells. Future studies on the in vivo efficacy and safety of saponin 6 for the treatment of GBM are warranted.

Dysregulated cell apoptosis may lead to malignant transformation, tumor progression and resistance to anticancer drugs (23). Molecules targeting apoptotic pathways are being actively developed for the treatment of cancer (24). To further investigate saponin 6-induced U87 MG cell death, cell apoptosis was assessed by flow cytometry using Annexin V-FITC/PI double staining. The results revealed that saponin 6 significantly induced U87 MG cell apoptosis in a dose-dependent manner. In addition, the majority of apoptotic 
A
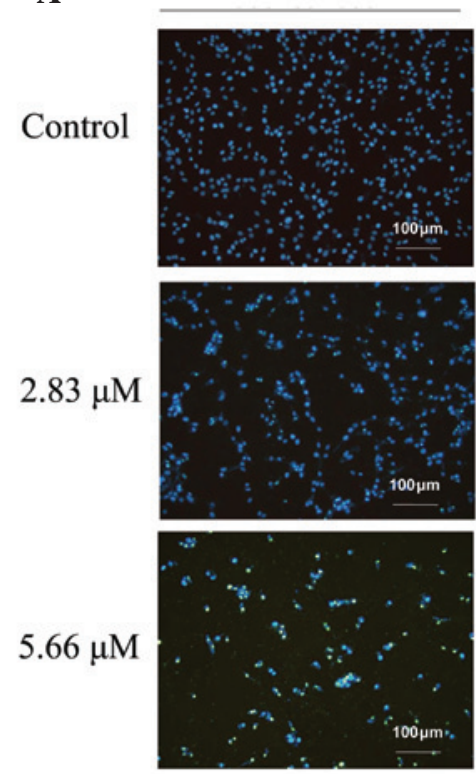

TUNEL
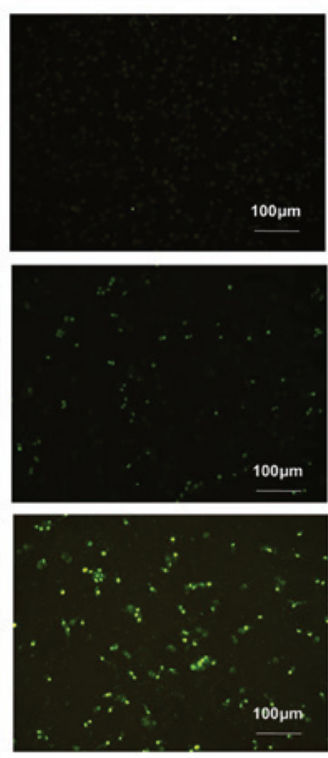
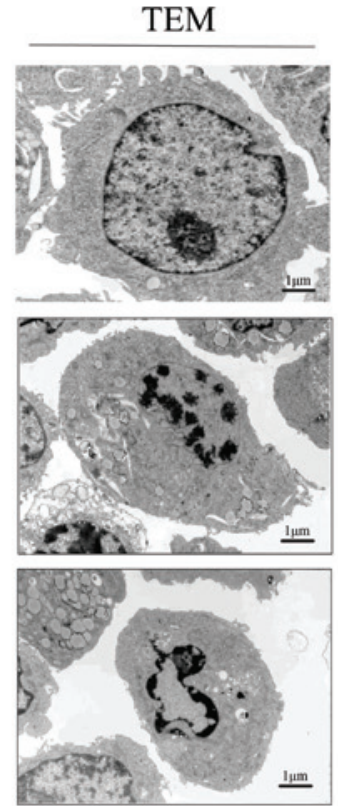

B

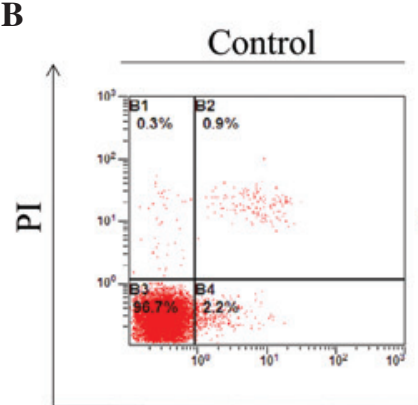

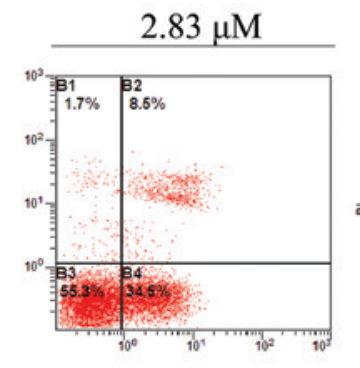

Annexin V-FITC
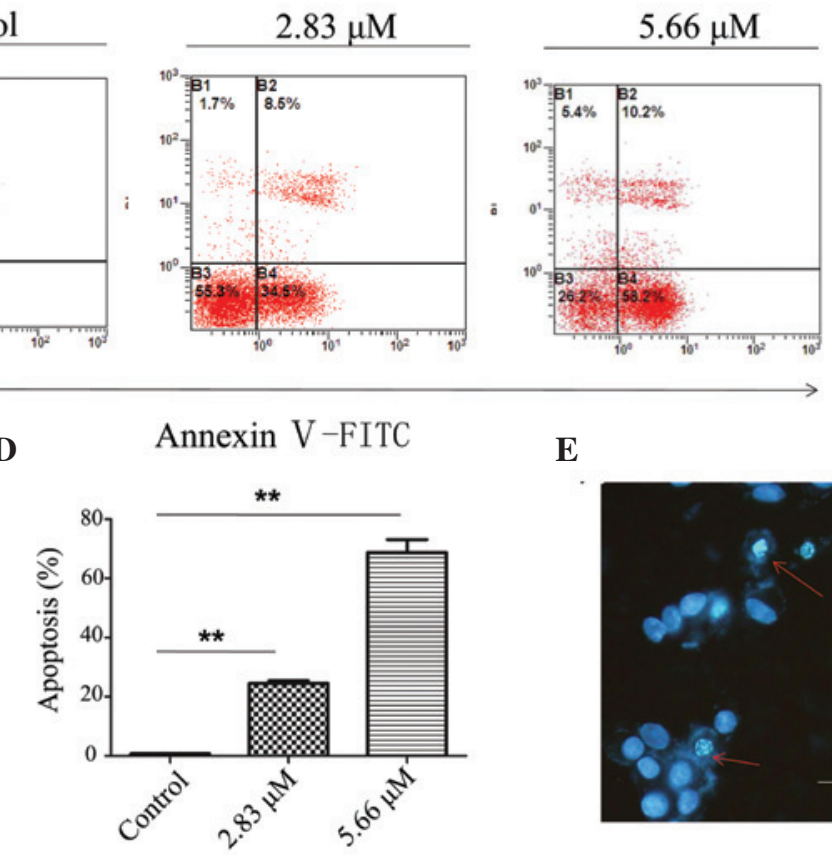

C

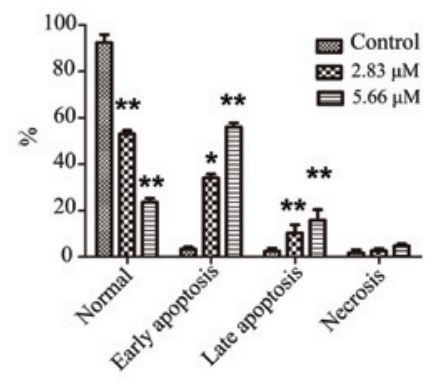

$\mathbf{E}$

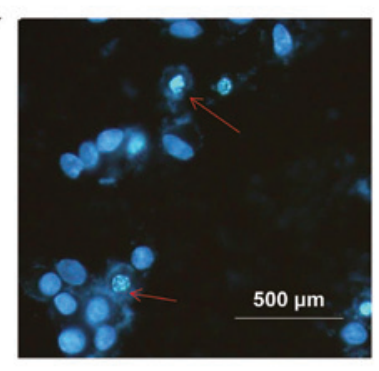

Figure 2. Saponin 6 causes DNA fragmentation, alters cell morphology, and induces apoptosis in human U87 MG malignant glioblastoma cells. Cells were treated with vehicle control, $2.83 \mu \mathrm{M}$ or $5.66 \mu \mathrm{M}$ saponin 6 for $24 \mathrm{~h}$. (A) DNA fragmentation and subcellular morphological alterations were examined by terminal deoxynucleotidyl transferase-mediated dUTP nick end labeling (TUNEL) staining and transmission electron microscopy, respectively. Annexin V-FITC/PI (B) quadrantal and (C) bar diagrams. (D) Cell apoptosis was determined by flow cytometry using Annexin V-fluorescein isothiocyanate (FITC)/propidium iodide (PI) double staining. (E) Fluorescence imaging with Hoechst 33342 staining. The red arrows indicate nuclear morphological changes characteristic of apoptosis, including chromatin condensation, boundary aggregation and splitting, and DNA fragmentation. B3, normal cells; B4, early apoptotic cells; B2, late apoptotic cells; B1, necrotic cells. Data are presented as the mean \pm standard deviation; $n=3$. ${ }^{*} \mathrm{P}<0.05$ and ${ }^{* *} \mathrm{P}<0.01$ vs. the vehicle control group.

cells were in the early stage of apoptosis following treatment with saponin 6 for $24 \mathrm{~h}$. A TUNEL assay and ultrastructural TEM study of saponin 6-treated cells detected DNA fragmentation and other nuclear morphological changes typical of apoptosis, including condensed, fractured and marginalized chromatin. Furthermore, Hoechst 33342 staining revealed the presence of pyknotic nuclei and apoptotic bodies in TUNEL-positive cells. These results provide evidence to suggest that saponin 6 may induce apoptosis in U87 MG cells.
In addition, increased levels of cell necrosis were detected following saponin 6 treatment; however, this accounted for only a very small fraction of cell death caused by saponin 6 . Therefore, saponin 6-induced U87 MG cell death was predominantly attributed to apoptosis. Furthermore, cell cycle distribution was analyzed by flow cytometry, which revealed that saponin 6 induced cell cycle arrest at $G_{0} / G_{1}$ phase, suggesting that saponin 6 may inhibit DNA synthesis in U87 MG cells. 


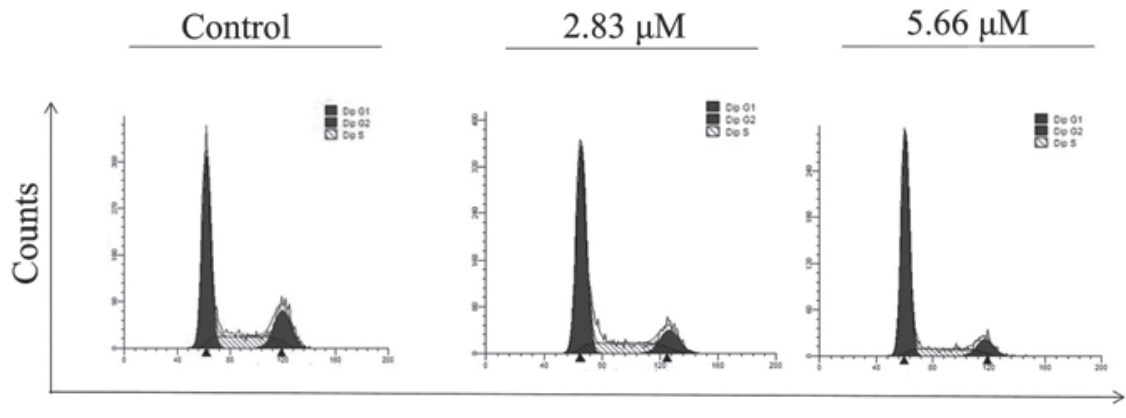

DNA Content

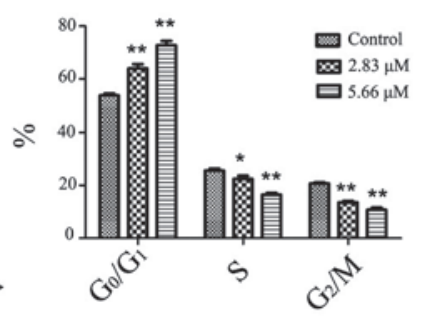

Figure 3. Saponin 6 induces $\mathrm{G}_{0} / \mathrm{G}_{1}$ cell cycle arrest in human U87 MG malignant glioblastoma cells. Cells were treated with vehicle control, $2.83 \mu \mathrm{M}$ or $5.66 \mu \mathrm{M}$ saponin 6 for $24 \mathrm{~h}$. Cell cycle progression was analyzed by flow cytometry and propidium iodide staining. Data are presented as the mean \pm standard deviation; $\mathrm{n}=3$. ${ }^{*} \mathrm{P}<0.05$ and ${ }^{* *} \mathrm{P}<0.01$ vs. the vehicle control group.

A
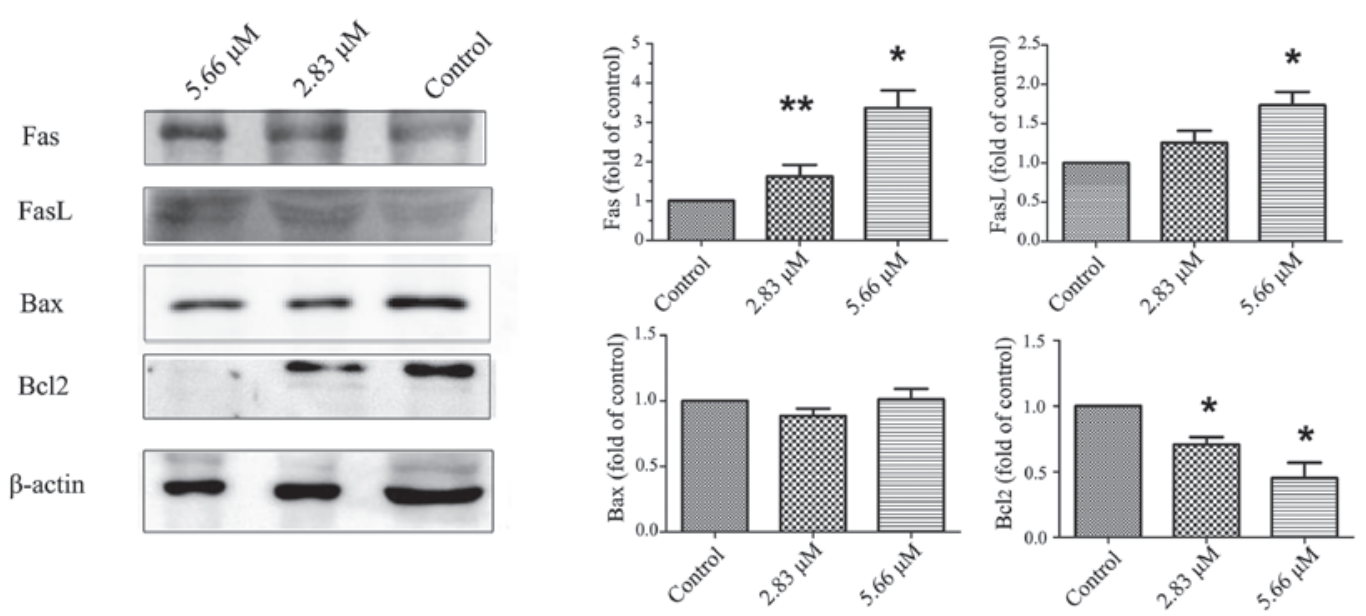

B

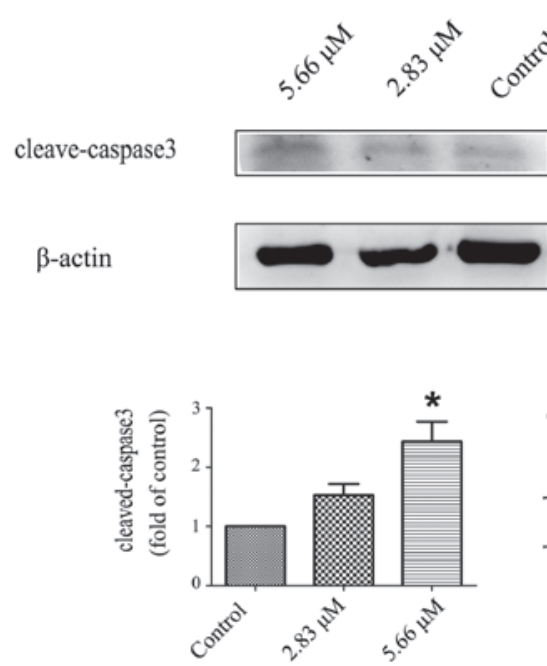

C

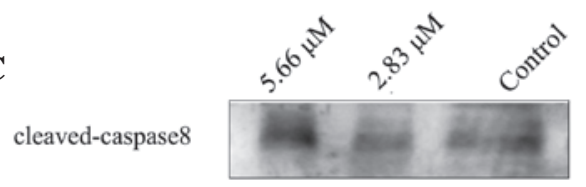

cleaved-caspase9

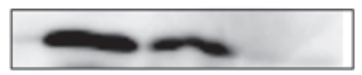

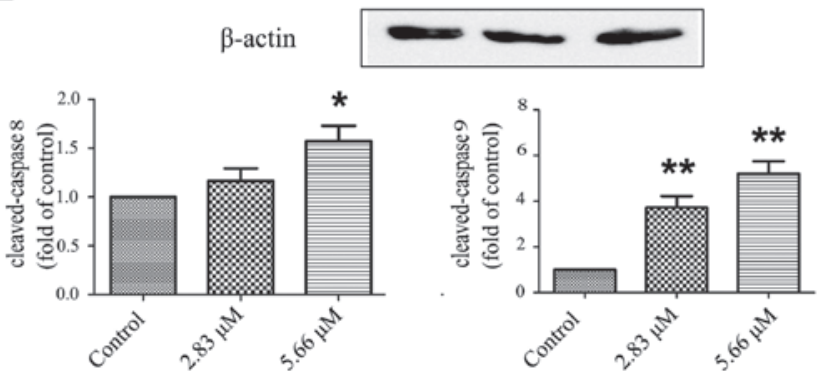

Figure 4. Saponin 6 activates the extrinsic and intrinsic apoptotic pathways in human U87 MG malignant glioblastoma cells. Cells were treated with vehicle control, $2.83 \mu \mathrm{M}$ or $5.66 \mu \mathrm{M}$ saponin 6 for 24 h. The protein expression levels of (A) Fas, Fas ligand (FasL), B-cell lymphoma 2 (Bcl-2) and Bcl-2-associated X protein (Bax); (B) cleaved caspase-3; and (C) cleaved caspase- 8 and -9 were determined by western blot analysis. Data are presented as the mean \pm standard deviation; $\mathrm{n}=5$. $\mathrm{P}<0.05$ and ${ }^{* *} \mathrm{P}<0.01$ vs. the vehicle control group.

Apoptosis can be triggered by extrinsic (death receptor) and intrinsic (mitochondrial) pathways. The extrinsic apoptotic pathway is initiated by death ligand binding to death receptors, such as tumor necrosis factor receptor 1 and Fas (25). The intrinsic apoptotic pathway, which is characterized by permeabilization of the mitochondria, release of cytochrome $c$ into 
the cytoplasm and activation of caspases, is under the tight regulation of Bcl-2 family proteins (26). Fas is expressed in the majority of glioma tissues, but not in normal brain tissues (25). It has previously been reported that the Fas pathway has a pivotal role in the tumorigenesis and progression of glioma (27). To investigate the apoptotic pathways involved in saponin 6-induced U87 MG cell apoptosis, the protein expression levels of Fas, its ligand FasL, and the Bcl-2 family proteins Bax (pro-apoptotic) and Bcl-2 (anti-apoptotic) were detected by western blot analysis. The results demonstrated that the protein expression levels of Fas and FasL were significantly increased following saponin 6 treatment. Furthermore, the protein expression levels of Bcl-2 were decreased following treatment with saponin 6, whereas the protein expression levels of Bax remained similar. These results suggested that both the extrinsic and intrinsic pathways may be involved in saponin 6-induced U87 MG cell apoptosis. In addition, the present study examined the activation of caspase- 8 and -9 , the initiator caspases for the extrinsic and intrinsic pathways, respectively, and caspase-3, an effector caspase involved in both pathways (28). The results demonstrated that the expression levels of cleaved caspase- $8,-9$ and -3 were significantly increased following treatment with saponin 6 . These results provide further evidence to suggest that saponin 6 is able to induce U87 MG cell apoptosis via both the extrinsic and intrinsic apoptotic pathways.

In conclusion, the present study demonstrated that saponin 6 derived from A. taipaiensis induced U87 MG cell death by inducing cell apoptosis via activation of both the intrinsic and extrinsic apoptotic pathways. Therefore, saponin 6 may have therapeutic potential for the treatment of GBM, and future studies regarding the in vivo efficacy and safety of saponin 6 are warranted.

\section{Acknowledgements}

The present study was supported by grants from the National Natural Science Foundation of China (grant nos. 81372457 and 81274029).

\section{References}

1. Stupp R, Mason WP, van den Bent MJ, Weller M, Fisher B, Taphoorn MJ, Belanger $\mathrm{K}$, Brandes AA, Marosi C, Bogdahn U, et al; European Organisation for Research and Treatment of Cancer Brain Tumor and Radiotherapy Groups; National Cancer Institute of Canada Clinical Trials Group: Radiotherapy plus concomitant and adjuvant temozolomide for glioblastoma. N Engl J Med 352: 987-996, 2005.

2. Magaña-Maldonado R, Manoutcharian K, Hernández-Pedro NY, Rangel-López E, Pérez-De la Cruz V, Rodríguez-Balderas C, Sotelo J and Pineda B: Concomitant treatment with pertussis toxin plus temozolomide increases the survival of rats bearing intracerebral RG2 glioma. J Cancer Res Clin Oncol 140: 291-301, 2014.

3. Oliva CR, Nozell SE, Diers A, McClugage SG III, Sarkaria JN, Markert JM, Darley-Usmar VM, Bailey SM, Gillespie GY, Landar A and Griguer CE: Acquisition of temozolomide chemoresistance in gliomas leads to remodeling of mitochondrial electron transport chain. J Biol Chem 285: 39759-39767, 2010.

4. Azevedo $\mathrm{H}$ and Moreira-Filho CA: Topological robustness analysis of protein interaction networks reveals key targets for overcoming chemotherapy resistance in glioma. Sci Rep 5: 16830, 2015.

5. Bodell WJ, Gaikwad NW, Miller D and Berger MS: Formation of DNA adducts and induction of lacI mutations in Big Blue Rat-2 cells treated with temozolomide: Implications for the treatment of low-grade adult and pediatric brain tumors. Cancer Epidemiol Biomarkers Prev 12: 545-551, 2003.
6. Johnson BE, Mazor T, Hong C, Barnes M, Aihara K, McLean CY, Fouse SD, Yamamoto S, Ueda H, Tatsuno K, et al: Mutational analysis reveals the origin and therapy-driven evolution of recurrent glioma. Science 343: 189-193, 2014.

7. Man S, Gao W, Zhang Y, Huang L and Liu C: Chemical study and medical application of saponins as anti-cancer agents. Fitoterapia 81: 703-714, 2010.

8. Son MK, Jung KH, Hong SW, Lee HS, Zheng HM, Choi MJ, Seo JH, Suh JK and Hong SS: SB365, Pulsatilla saponin D suppresses the proliferation of human colon cancer cells and induces apoptosis by modulating the AKT/mTOR signalling pathway. Food Chem 136: 26-33, 2013.

9. Wang XY, Chen XL, Tang HF, Gao H, Tian XR and Zhang PH: Cytotoxic triterpenoid saponins from the rhizomes of Anemone taipaiensis. Planta Med 77: 1550-1554, 2011.

10. Wang Y, Tang H, Zhang Y, Li J, Li B, Gao Z, Wang X, Cheng G and Fei Z: Saponin B, a novel cytostatic compound purified from Anemone taipaiensis, induces apoptosis in a human glioblastoma cell line. Int J Mol Med 32: 1077-1084, 2013.

11. Li J, Tang H, Zhang Y, Tang C, Li B, Wang Y, Gao Z, Luo P, Yin A, Wang X, et al: Saponin 1 induces apoptosis and suppresses $\mathrm{NF}-\kappa \mathrm{B}$-mediated survival signaling in glioblastoma multiforme (GBM). PloS One 8: e81258, 2013.

12. Wang K, Hu X, Du C, Tu S, Zhang F and Xie X: Angiotensin-(1-7) suppresses the number and function of the circulating fibrocytes by upregulating endothelial nitric oxide synthase expression. Mol Cell Biochem 365: 19-27, 2012.

13. Maekawa Y, Yagi K, Nonomura A, Kuraoku R, Nishiura E, Uchibori E and Takeuchi K: A tetrazolium-based colorimetric assay for metabolic activity of stored blood platelets. Thromb Res 109: 307-314, 2003.

14. Osbourn A, Goss RJ and Field RA: The saponins: Polar isoprenoids with important and diverse biological activities. Nat Prod Rep 28: 1261-1268, 2011.

15. Tian $X$, Tang $H$, Lin H, Cheng $G$, Wang $S$ and Zhang $X$ : Saponins: The potential chemotherapeutic agents in pursuing new anti-glioblastoma drugs. Mini Rev Med Chem 13: 1709-1724, 2013.

16. de Costa F, Yendo AC, Fleck JD, Gosmann G and Fett-Neto AG: Immunoadjuvant and anti-inflammatory plant saponins: Characteristics and biotechnological approaches towards sustainable production. Mini Rev Med Chem 11: 857-880, 2011.

17. Uzayisenga R, Ayeka PA and Wang Y: Anti-diabetic potential of Panax notoginseng saponins (PNS): A review. Phytother Res 28: 510-516, 2014.

18. Yang $\mathrm{X}$, Xiong $\mathrm{X}$, Wang $\mathrm{H}$ and Wang J: Protective effects of Panax notoginseng saponins on cardiovascular diseases: A comprehensive overview of experimental studies. Evid Based Complement Alternat Med 2014: 204840, 2014.

19. Wu N, Wu GC, Hu R, Li M and Feng H: Ginsenoside Rh2 inhibits glioma cell proliferation by targeting microRNA-128. Acta Pharmacol Sin 32: 345-353, 2011.

20. Zhou J, Cheng G, Cheng G, Tang HF and Zhang X: Novaeguinoside II inhibits cell proliferation and induces apoptosis of human brain glioblastoma U87MG cells through the mitochondrial pathway. Brain Res 1372: 22-28, 2011.

21. Lv L, Zheng L, Dong D, Xu L, Yin L, Xu Y, Qi Y, Han X and Peng J: Dioscin, a natural steroid saponin, induces apoptosis and DNA damage through reactive oxygen species: A potential new drug for treatment of glioblastoma multiforme. Food Chem Toxicol 59: 657-669, 2013.

22. Wang R, Xiao X, Wang PY, Wang L, Guan Q, Du C and Wang XJ: Stimulation of autophagic activity in human glioma cells by anti-proliferative ardipusilloside I isolated from Ardisia pusilla. Life Sci 110: 15-22, 2014.

23. Wong RS: Apoptosis in cancer: From pathogenesis to treatment. J Exp Clin Cancer Res 30: 87, 2011.

24. Millimouno FM, Dong J, Yang L, Li J and Li X: Targeting apoptosis pathways in cancer and perspectives with natural compounds from mother nature. Cancer Prev Res (Phila) 7: 1081-1107, 2014.

25. Thorburn A: Death receptor-induced cell killing. Cell Signal 16: 139-144, 2004.

26. Estaquier J, Vallette F, Vayssiere JL and Mignotte B: The mitochondrial pathways of apoptosis. Adv Exp Med Biol 942: 157-183, 2012.

27. Parney IF, Hao C and Petruk KC: Glioma immunology and immunotherapy. Neurosurgery 46: 778-791; discussion 791-792, 2000.

28. Tait SW and Green DR: Mitochondria and cell death: Outer membrane permeabilization and beyond. Nat Rev Mol Cell Biol 11: 621-632, 2010. 